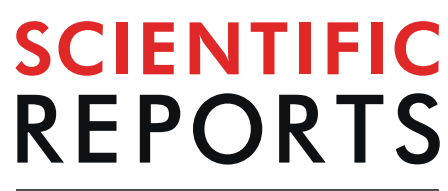

natureresearch

\title{
Potential chiral fluorescent molecular probes based on an $\alpha, \beta$-unsaturated ketone for anion detection
}

\author{
Congshu Li ${ }^{1}$, Lixia Liu ${ }^{1}$, Weitong Pan ${ }^{2}$, Yanmei Chen ${ }^{1}$, Xuefang Shang ${ }^{1 *}$, Yingling Wang ${ }^{1}$, \\ Tianyun Wang ${ }^{3}$ \& Xiufang $X_{u^{4}}$
}

A series of potential chiral compounds containing an $\alpha, \beta$-unsaturated ketone was developed for anion detection. The interplay of compounds and biological momentous anions $\left(\mathrm{Cl}^{-}, \mathrm{H}_{2} \mathrm{PO}_{4}^{-}, \mathrm{I}^{-}, \mathrm{AcO}^{-}, \mathrm{HS}^{-}\right.$, $\mathrm{F}^{-}$, and $\mathrm{Br}^{-}$) was evaluated by UV-vis experiments, fluorescence experiments, and electrochemical tests. By comparison, compound 1 had the best selectivity and compound 5 had the strongest binding ability among the five compounds. And compound 5 had the highest sensitivity to $\mathrm{H}_{2} \mathrm{PO}_{4}{ }^{-}$among the measured anions, and it also can be applied to actual samples, the content of $\mathrm{H}_{2} \mathrm{PO}_{4}{ }^{-}$tested in the potassium dihydrogen phosphate fertilizer solution reached above $97.5 \%$ of the marked content, and the recovery rates were within the range of $98.5-99.1 \%$, attesting that this method was reliable for the test of $\mathrm{H}_{2} \mathrm{PO}_{4}{ }^{-}$in fertilizer. Through HRMS titration, circular dichroism and optical rotation experiments, the probable interacted mechanism was proved that the interaction site was the $\mathrm{C}=\mathrm{C}$ of the $\alpha, \beta$-unsaturated ketone structure. In addition, the interacted mechanism was researched from the perspective of chirality. Furthermore, theoretical investigation analysis was introduced to reveal that the roles of molecular frontier orbitals in molecular interplay were determined. Therefore, this series of potential chiral compounds has potential application prospects in anion recognition.

Chirality is a universal feature in the universe, which is reflected in the emergence and evolution of life $\mathrm{e}^{1-3}$. With the continuous in-depth research on molecular recognition, chiral molecular recognition has become an important topic ${ }^{4-6}$. At the same time, with the increasing attention on the safety and environmental problems with using radioactive probes and the advantages of high sensitivity and good selectivity, fluorescent probes have been widely used in molecular recognition. In view of the important role of anions (such as $\mathrm{AcO}^{-}, \mathrm{HS}^{-}, \mathrm{F}^{-}, \mathrm{H}_{2} \mathrm{PO}_{4}^{-}$ etc.) in nature, a great deal of effort has been made within the field of supramolecular chemistry to devise and synthesize receptors capable of selectively identifying anions ${ }^{7-10}$. As a consequence, the development of novel molecular probes for anion sensors has been proven to be fairly active research domain ${ }^{11-21}$. However, there are few reports on potential chiral fluorescent molecular probes used to detect anions. Therefore, it is very important to use potential chiral fluorescent molecular probes to selectively detect anions.

Normally, an $\alpha, \beta$-unsaturated ketone is linked to fluorescent groups, which will result in weak or almost no fluorescence response of fluorescent probes due to suppression of photo-induced electronic transfer (PET). The nucleophilic additive reaction of anions with an $\alpha, \beta$-unsaturated ketone blocks the PET process and causes fluorescence recovery. Thus, we can detect the anions that we want ${ }^{22,23}$.

In this thesis, a string of potential chiral compounds containing an $\alpha, \beta$-unsaturated ketone structure was designed and synthesized (Scheme 1). The synthetic compounds displayed a high combination capacity for $\mathrm{AcO}^{-}$, $\mathrm{HS}^{-}, \mathrm{F}^{-}, \mathrm{H}_{2} \mathrm{PO}_{4}^{-}$in the sensing of different anions by UV-vis, fluorescence, electrochemical, circular dichroism and optical rotation experiments. Fortunately, the crystal of compound 1 was also obtained, which provided the foundation for the host-guest interaction.

${ }^{1}$ Key Laboratory of Medical Molecular Probes, School of Basic Medical Sciences, Xinxiang Medical University, Xinxiang, Henan, 453003, China. ${ }^{2}$ Queen Marry University of London, Nanchang University, Nanchang, Jiangxi, 330031, China. ${ }^{3}$ Department of Biochemistry, Xinxiang Medical University, Jinsui Road 601, Xinxiang, Henan, 453003, China. ${ }^{4}$ Department of Chemistry, Nankai University, Tianjin, 300071, China. *email: xuefangshang@126.com 
<smiles>[R]c1cc([R1])c(O)c(C=O)c1</smiles>

1: $\mathrm{R}_{1}=\mathrm{R}_{2}=\mathrm{H}$

2: $\mathrm{R}_{1}=\mathrm{R}_{2}=\mathrm{Br}$

3: $\mathrm{R}_{1}=\mathrm{H} ; \mathrm{R}_{2}=\mathrm{Br}$

4: $\mathrm{R}_{1}=\mathrm{NO}_{2} ; \mathrm{R}_{2}=\mathrm{H}$

5: $\mathrm{R}_{1}=\mathrm{H} ; \mathrm{R}_{2}=\mathrm{NO}_{2}$

Scheme 1. The route of synthesized compounds.

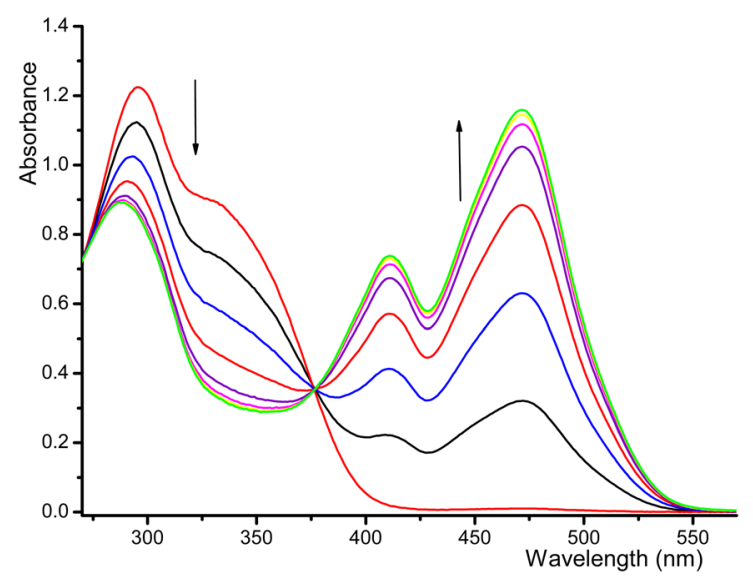

a<smiles>[R2]c1cc([R1])c(O)c(/C=C/C(=O)c2ccccc2)c1</smiles>

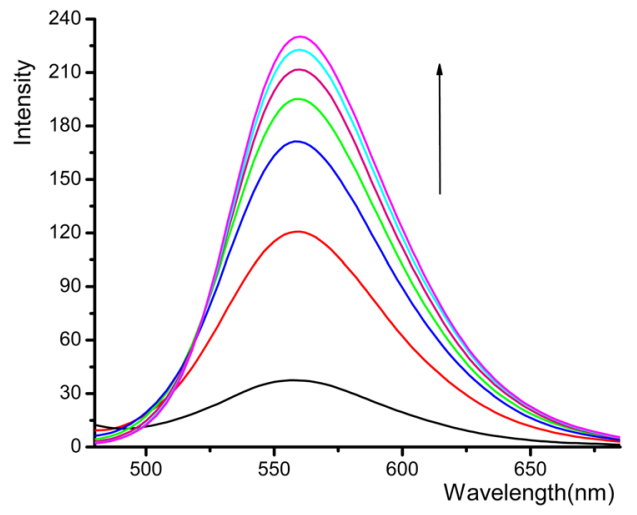

b

Figure 1. UV-vis spectral (a) and fluorescence (b) changes of compound $5\left(4 \times 10^{-5} \mathrm{~mol} \cdot \mathrm{L}^{-1}\right)$ upon the addition of $\mathrm{H}_{2} \mathrm{PO}_{4}^{-}$. All spectra were recorded in DMSO solution, (a) $\mathrm{H}_{2} \mathrm{PO}_{4}^{-}$: $\left((0-8) \times 10^{-5} \mathrm{~mol} \cdot \mathrm{L}^{-1}\right) ;(\mathbf{b}) \mathrm{H}_{2} \mathrm{PO}_{4}^{-}$: $\left.(0-20.8) \times 10^{-5} \mathrm{~mol} \cdot \mathrm{L}^{-1}\right), \lambda_{\mathrm{ex}}=412 \mathrm{~nm}$. Arrows indicated the direction of increasing anion concentration.

\section{Results and Discussion}

X-ray crystallography. The ethanol solution of compound 1 was placed so that the ethanol evaporated slowly and the single light-yellow crystal was separated. The determination of its crystal structure was carried out using X-ray diffraction analysis (see Supplementary Fig. S1). X-ray diffraction data for 1 was collected, and the structural refinement results were shown in Table S1. As shown in Fig. S2, hydrogen bonds were formed between two molecular compounds, which formed a "T" configuration. The hydrogen bonds formed were linked by $\mathrm{O}(1)$ $\mathrm{H}(1) \ldots \mathrm{O}(2) \# 1$. (see Supplementary Table S2 Symmetry transformations used to generate equivalent atoms: \#1 $-\mathrm{x}$ $+5 / 2, y+1 / 2,-z+1 / 2)$. Additionally, $\pi-\pi$ stacking of different " $T$ " configurations formed a stratified structure.

UV-vis titration. The combining capacities of probes (1-5) with anions $\left(\mathrm{H}_{2} \mathrm{PO}_{4}^{-}, \mathrm{AcO}^{-}, \mathrm{HS}^{-}, \mathrm{F}^{-}, \mathrm{Cl}^{-}, \mathrm{I}^{-}\right.$and $\mathrm{Br}^{-}$) in DMSO solution were investigated via UV-vis spectroscopy. Results manifested that these compounds (1-5) showed different binding abilities for anions. As seen in Figs. S3a, S4, compound 1 took on two intense absorption bands at at approximately 292 and $365 \mathrm{~nm}$, while the remarkable absorption band gradually arose at approximately $500 \mathrm{~nm}$ with the gradual addition of $\mathrm{F}^{-}$and $\mathrm{H}_{2} \mathrm{PO}_{4}{ }^{-}$. Simultaneously, the strengths of the absorption peaks at 292 and $365 \mathrm{~nm}$ decreased. A distinct isoabsorptive point was noted at $376 \mathrm{~nm}$ and it turned out that 1 and $\mathrm{H}_{2} \mathrm{PO}_{4}^{-}$formed a stable complex in a certain proportion. The binding of $\mathrm{H}_{2} \mathrm{PO}_{4}^{-}, \mathrm{AcO}^{-}, \mathrm{HS}^{-}, \mathrm{F}^{-}$to compound 4, and $\mathrm{H}_{2} \mathrm{PO}_{4}^{-}$, Aco ${ }^{-}, \mathrm{F}^{-}$and $\mathrm{HS}^{-}$to 5 produced phenomenona similar to that of $\mathrm{H}_{2} \mathrm{PO}_{4}^{-}$to 1 (see Fig. 1a, Supplementary Figs. S3d, S7, S8). However, the excessive addition of else anions induced only the faint changes and even could be overlooked in the UV-vis spectra. For compounds 2 with two electron-withdrawing groups $(-\mathrm{Br})$, it had two peaks at $320,360 \mathrm{~nm}$. After the addition of $\mathrm{H}_{2} \mathrm{PO}_{4}^{-}, \mathrm{AcO}^{-}$and $\mathrm{F}^{-}$, the peak increased at $320 \mathrm{~nm}$, decreased at $360 \mathrm{~nm}$, and formed a new peak at $500 \mathrm{~nm}$, forming isoabsorptive points at 330 and $410 \mathrm{~nm}$. (see Supplementary Figs. S3b, S5). Compounds 3 with $\mathrm{H}_{2} \mathrm{PO}_{4}^{-}, \mathrm{AcO}^{-}, \mathrm{HS}^{-}, \mathrm{F}^{-}$showed the same occurrences, while the other ions showed little change (see Supplementary Figs. S3c, S6). Additionally, the absorption intensity of compound 2 (3,5-dibromosalicylaldehyde derivative) was stronger than that of compound 3 (5-bromosalicylaldehyde derivative). This was due to the fact that two - $\mathrm{Br}$ have more electron-withdrawing property than one-Br. The binding spectra of probes $1,4,5$ and anion were different from that of 2,3 due to the different substituents. In comparison, compound 5 had the largest spectral change in combination with anions among the five compounds, followed by 2 , possibly because $-\mathrm{NO}_{2}$ showed stronger electron-withdrawing property than $-\mathrm{Br}$, which was conducive to nucleophilic addition, and increased the combining ability of $\mathrm{C}=\mathrm{C}$ in compounds 


\begin{tabular}{|l|l|l|l|l|l|}
\hline Anion $^{\mathrm{a}}$ & $\mathrm{HS}^{-}$ & $\mathrm{F}^{-}$ & $\mathrm{AcO}^{-}$ & $\mathbf{H}_{2} \mathbf{P O}_{4}^{-}$ & $\mathrm{Cl}^{-}, \mathbf{B r}^{-} \mathbf{I}^{-}$ \\
\hline$K \mathrm{~S}_{1}$ & $\mathrm{ND}^{\mathrm{b}}$ & $(2.29 \pm 0.66) \times 10^{4 \mathrm{c}}$ & $\mathrm{ND}^{\mathrm{b}}$ & $(1.87 \pm 0.08) \times 10^{2 \mathrm{c}}$ & $\mathrm{ND}^{\mathrm{b}}$ \\
\hline$K \mathrm{~s}_{2}$ & $(3.84 \pm 1.25) \times 10^{2 \mathrm{c}}$ & $(3.61 \pm 0.51) \times 10^{3 \mathrm{c}}$ & $(3.25 \pm 0.11) \times 10^{3 \mathrm{c}}$ & $(1.53 \pm 0.18) \times 10^{4 \mathrm{c}}$ & $\mathrm{ND}^{\mathrm{b}}$ \\
\hline $\mathrm{Ks}_{3}$ & $\mathrm{ND}^{\mathrm{b}}$ & $(9.80 \pm 2.75) \times 10^{3 \mathrm{c}}$ & $(5.44 \pm 0.71) \times 10^{3 \mathrm{c}}$ & $(1.43 \pm 0.12) \times 10^{4 \mathrm{c}}$ & $\mathrm{ND}^{\mathrm{b}}$ \\
\hline$K \mathrm{~s}_{4}$ & $(1.15 \pm 0.07) \times 10^{3 \mathrm{c}}$ & $(3.50 \pm 0.22) \times 10^{3 \mathrm{c}}$ & $(1.59 \pm 0.11) \times 10^{3 \mathrm{c}}$ & $(8.09 \pm 0.38) \times 10^{3 \mathrm{c}}$ & $\mathrm{ND}^{\mathrm{b}}$ \\
\hline$K \mathrm{~s}_{5}$ & $(2.51 \pm 0.50) \times 10^{3 \mathrm{c}}$ & $(1.07 \pm 0.61) \times 10^{3 \mathrm{c}}$ & $(2.96 \pm 0.74) \times 10^{3 \mathrm{c}}$ & $(4.00 \pm 0.13) \times 10^{5 \mathrm{c}}$ & $\mathrm{ND}^{\mathrm{b}}$ \\
\hline
\end{tabular}

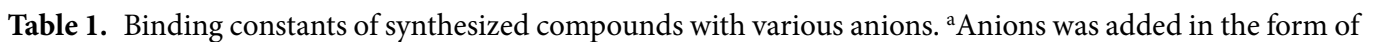
sodium sulfide or tetra- $n$-butylammonium salts. ${ }^{\mathrm{b}}$ The spectra changed little and the binding constant could not be determined. 'The binding ratio is $1: 1$.

and ions. While the $-\mathrm{NO}_{2}$ located in the 3-position of the salicylaldehyde was weaker than that of the 5-position of the salicylaldehyde, which may be due to steric hindrance.

Fluorescence response. The interactions of detected anions and compounds (1-5) can also be studied by changes in fluorescence before and after the reaction. The free compound 1 exhibited a peak at $492 \mathrm{~nm}$. When different anions including $\mathrm{H}_{2} \mathrm{PO}_{4}{ }^{-}$(see Supplementary Fig. S9a), $\mathrm{F}^{-}$(see Supplementary Fig. S10a), and AcO(see Supplementary Fig. S10b) were titrated into a DMSO solution of compound 1, its fluorescence intensity progressively strengthened at $600 \mathrm{~nm}$, and a fresh absorption peak appeared. When excessive $\mathrm{Cl}^{-}, \mathrm{Br}^{-}, \mathrm{I}^{-}$and $\mathrm{HS}^{-}$ions were added, there was almost no influence on the fluorescence intensity. The fluorescence spectral response of compound 5 was so weak that it can be almost ignored. Then, the fluorescence band with $560 \mathrm{~nm}$ as the center was heightened with the dripping of $\mathrm{H}_{2} \mathrm{PO}_{4}{ }^{-}$(see Fig. 1b), $\mathrm{F}^{-}$(see Supplementary Fig. S12a), $\mathrm{AcO}^{-}$(see Supplementary Fig. S12b), and $\mathrm{HS}^{-}$(see Supplementary Fig. S12c) into compound 5. Similar changes in the fluorescence spectra occurred in the addition of $\mathrm{H}_{2} \mathrm{PO}_{4}^{-}$(see Fig. S9a), $\mathrm{F}^{-}$(see Supplementary Fig. S11a), AcO ${ }^{-}$(see Supplementary Fig. S11b), and HS- (see Supplementary Fig. S11c) to compound 2 and $\mathrm{H}_{2} \mathrm{PO}_{4}^{-}$to compounds 3 (see Supplementary Fig. S9c) and 4 (see Supplementary Fig. S9d). The additions of other anions caused little or no change and therefore can be ignored. Two possible mechanisms to account for the above fluorescence enhancement were exploited: (1) suppression of PET and (2) the rigidity of the host molecule induced by the binding guest $^{24,25}$. Free compounds exhibited a weak fluorescence response, and the reason might be that without the additions of anions, the hydrogen atom on the hydroxyl group $(-\mathrm{OH})$ of the free compound could form intermolecular hydrogen bonds with the oxygen atom of the $\alpha, \beta$-unsaturated ketone (see Supplementary Fig. S2), leading to photoinduced electron transfer. However, electrons were shifted from the compound to the fluorophore when the anion was added to the compound solution, which led to enhancement of the emission intensity.

Binding constants. The complexes were obtained by combining the compounds (1-5) with anions in a proportion of 1:1 through the analysis of the Job plots. The binding constants derived from the non-linear square method using UV-vis titration were shown in Table $1^{26,27}$. From Table 1, compounds (2-5) with electron-withdrawing group showed the following binding ability sequence: $\mathrm{H}_{2} \mathrm{PO}_{4}^{-}>\mathrm{F}^{-}>\mathrm{AcO}^{-}>\mathrm{HS}^{-}>\mathrm{Cl}^{-}$, $\mathrm{I}^{-}, \mathrm{Br}^{-}$. The reason may be that (1) nucleophilicity of anion; (2) spatial matching between probes and anions; (3) hydrogen bonding between host and guest. The tetrahedral space configuration of $\mathrm{H}_{2} \mathrm{PO}_{4}{ }^{-}$had a higher spatial fit with the compounds, and it can form hydrogen bonds with the probes ${ }^{24,25}$. The reason why compound 5 had the strongest ability to bind $\mathrm{H}_{2} \mathrm{PO}_{4}{ }^{-}$might be that as an electron-withdrawing group, the 5-position nitro group enhanced the combining capacity of the $\mathrm{C}=\mathrm{C}$ of compound 5 with $\mathrm{H}_{2} \mathrm{PO}_{4}{ }^{-}$. However, compound 1 without electron-withdrawing group showed high sensitivity for $\mathrm{F}^{-}$with spherical structure in different anions, which may be related to steric hindrance. It also can be found from the data in the Table 1 that electron-withdrawing groups could enhance the binding ability of compounds with anions.

Taking $\mathrm{H}_{2} \mathrm{PO}_{4}{ }^{-}$as example, HRMS (ESI) was used to study the mechanism of compounds binding to anions. As shown in Fig. 2a, a new molecular ion peak appeared at $\mathrm{m} / \mathrm{z}=366.0324(\mathrm{M}-\mathrm{H})^{-}\left(5-\mathrm{H}_{2} \mathrm{PO}_{4}^{-}\right)$after adding $\mathrm{H}_{2} \mathrm{PO}_{4}{ }^{-}$to compound 5. Considering the above work, the reaction mechanism of the compounds and $\mathrm{H}_{2} \mathrm{PO}_{4}{ }^{-}$ may have two forms: (1) the nucleophilic reaction of $\mathrm{H}_{2} \mathrm{PO}_{4}{ }^{-}$and the electron-deficient $\mathrm{C}=\mathrm{C}$; and (2) hydrogen bond formation between the $-\mathrm{OH}$ of salicylaldehyde and $\mathrm{H}_{2} \mathrm{PO}_{4}{ }^{-}$(Fig. 2b) ${ }^{10,11}$.

Detection limit. As compound 5 had the strongest binding ability, so taking it for example, the linear relationship between compound 5 and $\mathrm{H}_{2} \mathrm{PO}_{4}^{-}, \mathrm{F}^{-}, \mathrm{HS}^{-}, \mathrm{AcO}^{-}$in DMSO solution was determined by UV-vis titration. The absorption value of compound $5\left(4 \times 10^{-6} \mathrm{~mol} \cdot \mathrm{L}^{-1}\right)$ at $470 \mathrm{~nm}$ was 0.049 , the molar absorption coefficient was calculated as $31005 \mathrm{~L} \cdot \mathrm{mol}^{-1} \cdot \mathrm{cm}^{-1}$. As can be seen from the Figure S13a, when the concentration of $\mathrm{AcO}^{-}$varies within the range of $0-10^{-2} \mathrm{~mol} \cdot \mathrm{L}^{-1}$, the UV-vis absorption value of compound 5 had a linear relationship with the concentration of $\mathrm{AcO}^{-}$, and the correlation coefficient was above 0.99 . The absorption value of compound 5 risied with the addition of $\mathrm{AcO}^{-}$, until the concentration of $\mathrm{AcO}^{-}$increased to $7.36 \times 10^{-3} \mathrm{~mol} \cdot \mathrm{L}^{-1}$, the absorption value of compound 5 rised to 1.3 times $^{28}$, which means the detection limit of compound 5 to $\mathrm{AcO}^{-}$ was $7.36 \times 10^{-3} \mathrm{~mol} \cdot \mathrm{L}^{-1}$. With the same method and the same conditions, the detection limit of 5 to $\mathrm{HS}^{-}$was $8 \times 10^{-5} \mathrm{~mol} \cdot \mathrm{L}^{-1}$ (see Supplementary Fig. S13b), that of $\mathrm{F}^{-}$was $4.8 \times 10^{-5} \mathrm{~mol} \cdot \mathrm{L}^{-1}$ (see Supplementary Fig. S13c), and that of $\mathrm{H}_{2} \mathrm{PO}_{4}{ }^{-}$was $1.2 \times 10^{-5} \mathrm{~mol} \cdot \mathrm{L}^{-1}$ (see Supplementary Fig. S13d). According to the above data, the order of the anions sensitivity of the compound 5 was $\mathrm{H}_{2} \mathrm{PO}_{4}^{-}>\mathrm{F}^{-}>\mathrm{HS}^{-}>\mathrm{AcO}^{-}$. 


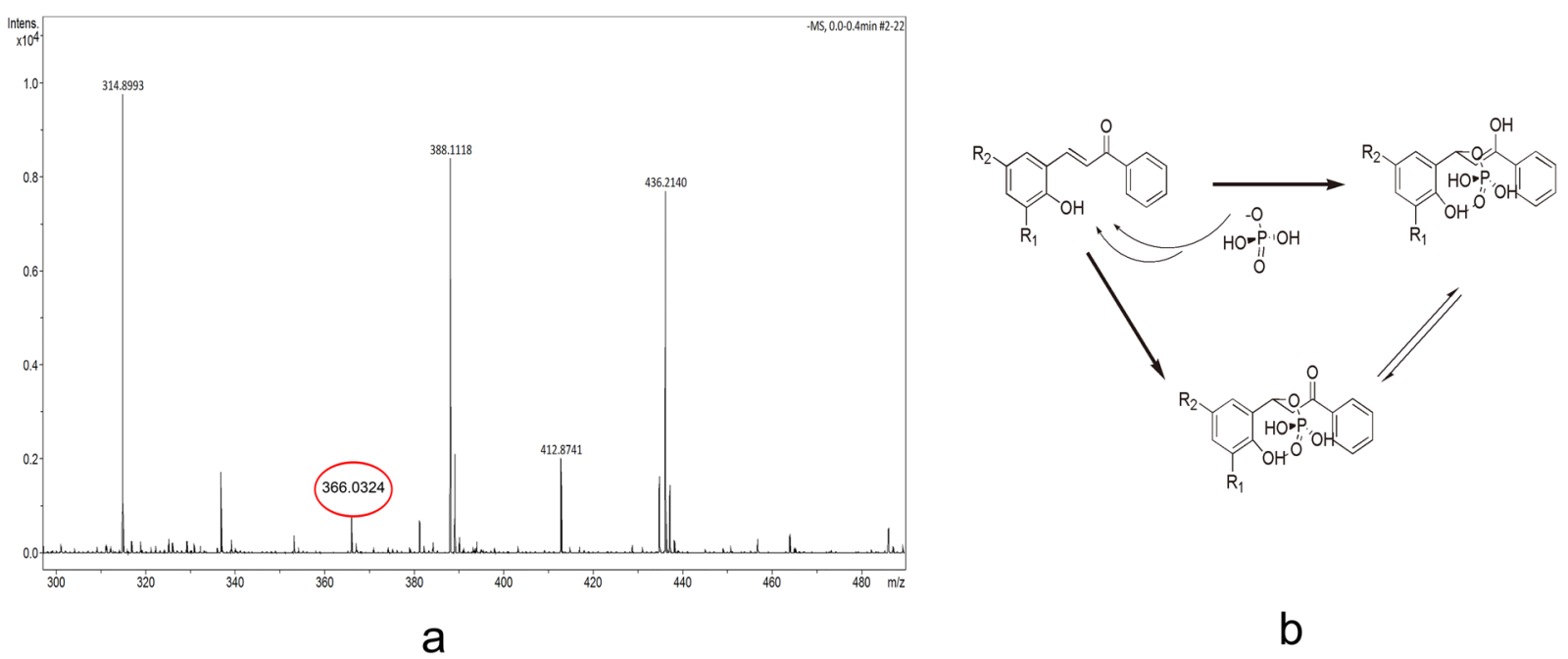

Figure 2. (a) ESI-HRMS spectrum of compound 5 after addition of $\mathrm{H}_{2} \mathrm{PO}_{4}^{-}$in DMSO solution. HRMS(ESI) $(\mathrm{m} / \mathrm{z}): 366.0324(\mathrm{M}-\mathrm{H})^{-}$; and $(\mathbf{b})$ interaction mechanism between $\mathrm{H}_{2} \mathrm{PO}_{4}{ }^{-}$and the compounds.

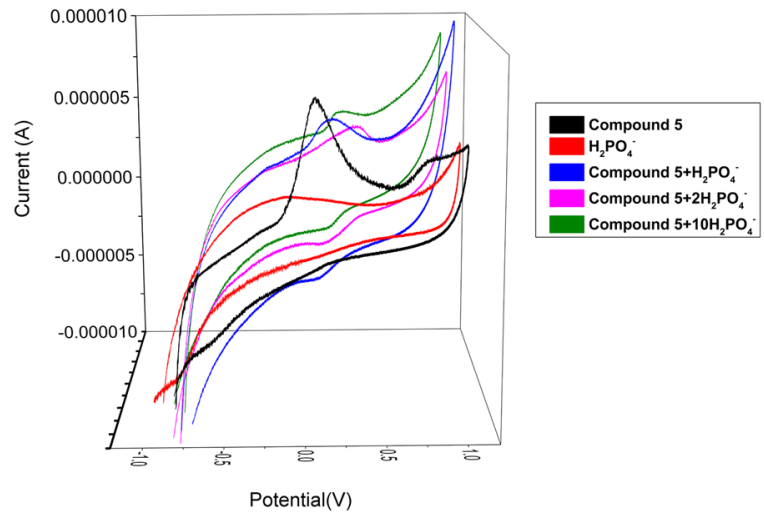

Figure 3. Cyclic voltammetry of compound 5 and Compound $5-\mathrm{H}_{2} \mathrm{PO}_{4}^{-}$.

Electrochemical experiment. In order to further explore the synthesized compound as anion probe, compound 5 was taken as an example to conduct cyclic voltammetry study in DMSO. Saturated sodium chloride solution was used as the electrolyte solution, a platinum electrode was the assistant electrode, and a calomel electrode was the reference electrode. In addition, a glassy carbon electrode was selected as the working electrode. The scan range was $-1 \mathrm{~V}$ to $1 \mathrm{~V}$, and the scanning speed was set to $50 \mathrm{mV} \cdot \mathrm{s}^{-1}$. Figure 3 showed the cyclic voltammetry behavior when compound 5 interacted with $\mathrm{H}_{2} \mathrm{PO}_{4}^{-}$. At $0.8 \mathrm{~V}$, compound 5 had a weak oxidation peak, while it had an obvious oxidation peak at $0.1 \mathrm{~V}$. After adding $\mathrm{H}_{2} \mathrm{PO}_{4}^{-}$, the oxidation peak of $0.8 \mathrm{~V}$ disappeared, and there was a new reduction peak near $0.1 \mathrm{~V}$. Moreover, as the concentration of $\mathrm{H}_{2} \mathrm{PO}_{4}{ }^{-}$increased, the anodic peak and the cathodic peak potentials both moved in the positive direction, and the current gradually decreased. After $\mathrm{HS}^{-}$was added, the oxidation peaks disappeared and a weak reduction peak appeared at $-0.6 \mathrm{~V}$. And the current decreased gradually (see Supplementary Fig. S14a). With the addition of $\mathrm{AcO}^{-}$(see Supplementary Fig. S14b) and $\mathrm{F}^{-}$(see Supplementary Fig. S14c), the oxidation peak of $0.8 \mathrm{~V}$ disappeared, the oxidation peak at $0.1 \mathrm{~V}$ moved in a negative direction, and a new reduction peak appeared near $0.4 \mathrm{~V}$, and the peaks currents decreased with the increasing of anions concentration. The changes in the figures were explained by the formation of complexes between compound 5 and $\mathrm{AcO}^{-}, \mathrm{F}^{-}, \mathrm{H}_{2} \mathrm{PO}_{4}{ }^{-}$. The oxidation peak of compound 5 at $0.8 \mathrm{~V}$ may be the characteristic peak of $\alpha, \beta$-unsaturated ketone, and the peak at $0.1 \mathrm{~V}$ may be the characteristic peak of $-\mathrm{NO}_{2}$. As compound 5 reacted with $\mathrm{AcO}^{-}, \mathrm{F}^{-}$, and $\mathrm{H}_{2} \mathrm{PO}_{4}^{-}$, new redox systems were formed, the redox reaction of compound 5 gradually weakened, and the $\alpha, \beta$-unsaturated ketone system was destroyed, so the oxidation peak at $0.8 \mathrm{~V}$ disappeared. The addition of $\mathrm{Cl}^{-}, \mathrm{Br}^{-}$, and $\mathrm{I}^{-}$caused almost no change in the redox signal intensity of compound 5 (see Supplementary Fig. S14d). This indicated that there was little electrochemical reaction between $\mathrm{Cl}^{-}, \mathrm{Br}^{-}$or $\mathrm{I}^{-}$and compound $5^{29}$.

Circular dichroism. Circular dichroism is a new method for studying potential chiral and stereoscopic structures of molecules, but it is seldom used in anion detection. Therefore, compound 5 was taken as an example to verify the interaction mechanism between compound and anions from the perspective of chirality through circular dichroism experiment. As shown in Fig. 4a, in DMSO, $\mathrm{H}_{2} \mathrm{PO}_{4}{ }^{-}$was achiral, and thus, it had no circular 


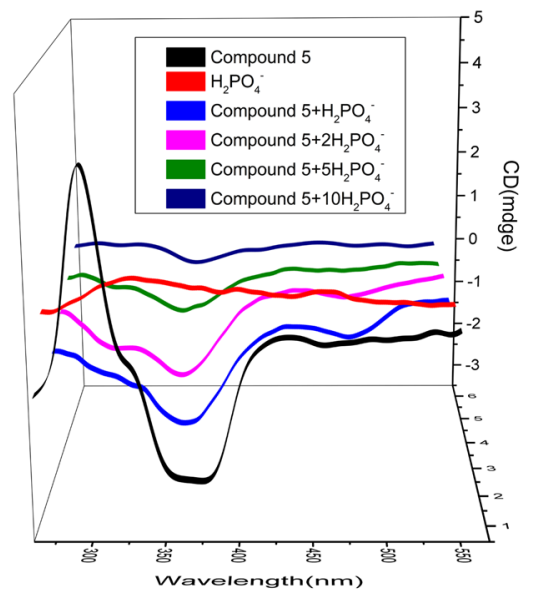

a

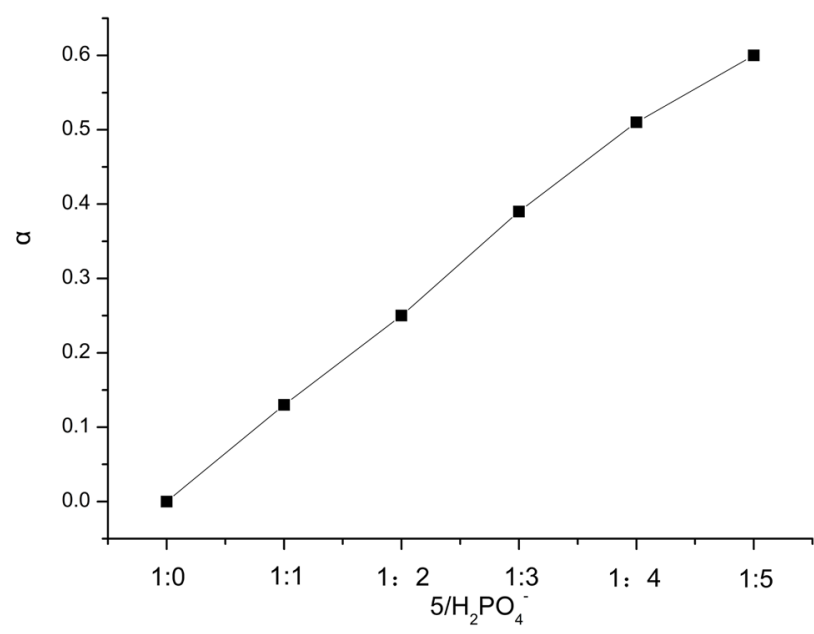

b

Figure 4. (a) The circular dichromatic spectra of $\mathrm{H}_{2} \mathrm{PO}_{4}^{-}$, compound 5 , compound 5 toward the addition of 1 , 2, 5, 10 equiv. $\mathrm{H}_{2} \mathrm{PO}_{4}{ }^{-}$in DMSO (b)the change in optical rotation of compound 5 after binding with $\mathrm{H}_{2} \mathrm{PO}_{4}{ }^{-}$in DMSO.

dichroism absorption. However, compound $5 \mathrm{had}$ a positive characteristic absorption peak at $285 \mathrm{~nm}$ and a negative peak at $360 \mathrm{~nm}$. This was due to ${ }^{30,31}$ the fact that when a vinyl group was conjugated with a carbonyl group, the $\mathrm{n} \rightarrow \pi^{*}$ transition of the carbonyl group occurred in the long-wave direction at 320-360 nm, at the same time, a strong $\pi \rightarrow \pi^{*}$ band appeared at $240 \mathrm{~nm}$. According to Woodward's rules and related to the environment of the chromophore, the circular dichromatic peak of compound 5 in the Fig. $4 \mathrm{a}$ appeared. When compound 5 reacted with $\mathrm{H}_{2} \mathrm{PO}_{4}^{-}$, the structure of $\alpha, \beta$-unsaturated ketone was destroyed. Therefore, with the continuous addition of $\mathrm{H}_{2} \mathrm{PO}_{4}^{-}$, the peak at $285 \mathrm{~nm}$ disappeared and the peak strength at $360 \mathrm{~nm}$ decreased. The same phenomenon occurred with the addition of $\mathrm{HS}^{-}, \mathrm{AcO}^{-}$and $\mathrm{F}^{-}$(see Supplementary Fig. S15). But, in methanol solvent, compound 5 had a positive peak at $290 \mathrm{~nm}$, and when it combined with ions, the positive peak disappeared. This may be due to $\alpha, \beta$-unsaturated ketone keto-enol tautomerism ${ }^{24,25}$ and solvent effect. In DMSO, there were intermolecular hydrogen bonds between two molecules (see Supplementary Fig. S2), so the main form of existence was ketone. However, as methanol is a protic solvent, it is easy to form hydrogen bonds with hydroxyl groups in the compound, which destroyed the original hydrogen bonds. Therefore, the main form of existence may be enol form. So the carbonyl peak at $360 \mathrm{~nm}$ vanished. As a result, the interaction of compound 5 and ions had different circular dichroism spectra in methanol and DMSO. The above outcome confirmed that the action site was the $\mathrm{C}=\mathrm{C}$ of the $\alpha, \beta$-unsaturated ketone structure, which verified the mechanism shown in Fig. $2 \mathrm{~b}$ above.

Specific rotation. Again, take the reaction of compound 5 with $\mathrm{H}_{2} \mathrm{PO}_{4}^{-}$, we did the optical rotation experiment to verify further. In the DMSO, the value of $[\alpha]_{5}$ was $0.0\left(0.004 \mathrm{~mol} \cdot \mathrm{L}^{-1}\right.$ in DMSO), when compound 5 was combined with $\mathrm{H}_{2} \mathrm{PO}_{4}{ }^{-}$, the optical rotation increased continuously. When $\mathrm{H}_{2} \mathrm{PO}_{4}{ }^{-}$was added to five equiv., $[\alpha]_{5-\mathrm{H} 2 \mathrm{PO} 4}{ }^{-}=0.6\left(0.004 \mathrm{~mol} \cdot \mathrm{L}^{-1}\right.$ in DMSO$)($ Fig. $4 \mathrm{~b})$. Combined with the circular dichroism spectra, this may be due to that the positive and negative peak intensities of compound 5 were almost identical and cancel each other out, so the optical rotation was 0 . When $\mathrm{H}_{2} \mathrm{PO}_{4}{ }^{-}$was added, only the absorption peak of carbonyl group was left, so it had optical rotation. When methanol was the solvent, the value of $[\alpha]_{5}$ was $0.6\left(0.004 \mathrm{~mol} \cdot \mathrm{L}^{-1}\right.$ in $\left.\mathrm{CH}_{3} \mathrm{OH}\right)$. When the added $\mathrm{H}_{2} \mathrm{PO}_{4}{ }^{-}$was $1: 1$ with compound 5 , the value of $[\alpha]_{5-\mathrm{H} 2 \mathrm{PO} 4}{ }^{-}$was $0.5\left(0.004 \mathrm{~mol} \cdot \mathrm{L}^{-1}\right.$ in $\left.\mathrm{CH}_{3} \mathrm{OH}\right)$, When the ratio was $1: 5$, the value of $[\alpha]_{5-\mathrm{H} 2 \mathrm{PO} 4}{ }^{-}$was $0.0\left(0.004 \mathrm{~mol} \cdot \mathrm{L}^{-1}\right.$ in $\left.\mathrm{CH}_{3} \mathrm{OH}\right)$, The optical activity disappeared (see Supplementary Fig. S16). The reaction of compound 5 and $\mathrm{H}_{2} \mathrm{PO}_{4}{ }^{-}$in methanol and DMSO had opposite results due to solvent effect. The specific reasons have been explained in the circular dichroism section. The experiments confirmed the above conclusion of circular dichroism experiment.

Theoretical investigation. In order to obtain further structural information, the calculation of compound 1 was implemented in Gaussian 03. Its geometric configuration optimization (Fig. 5a) was accomplished by density functional theory combined with the B3LYP exchange correlation function and 3-21 G basis set ${ }^{32}$. Comparison of bond lengths (see Supplementary Table S3) and angles (see Supplementary Table S4) between the $\mathrm{X}$-ray diffraction crystal structure and theoretically optimized model structure of compound 1 shows that the two data sets were basically consistent. The differences in the data may be caused by the fact that most optimizations were obtained under the gas phase conditions, and the difference in the base group and method used for calculation could be neglected. Therefore, this manifested the veracity of the theoretical method ${ }^{33,34}$. Meanwhile, we could know that 1 had no intramolecular hydrogen bonds. The literature ${ }^{35,36}$ stated clearly that intramolecular hydrogen bonding and electron-withdrawing group can heighten the anion binding ability. Therefore, this could explain why compound 1 had a very weak anionic binding capacity, which also could be proven by the UV-vis and fluorescence experiments. 

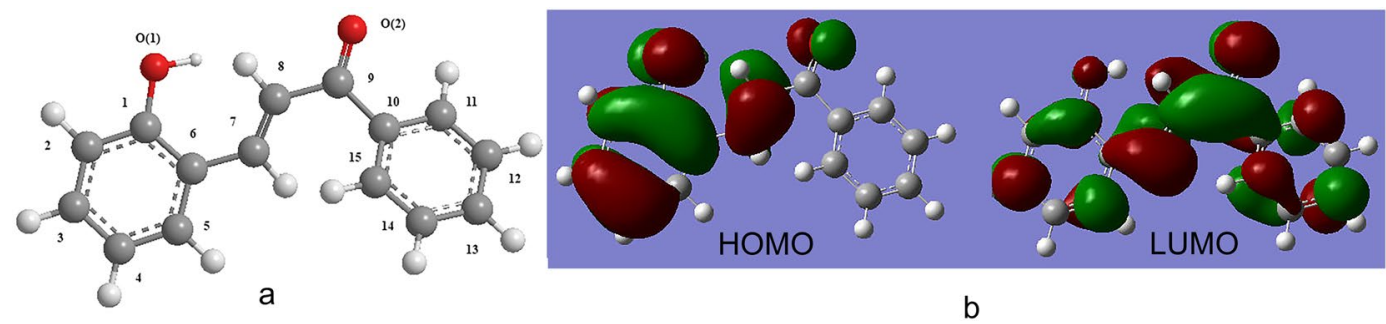

Figure 5. (a) The geometry of compound $\mathbf{1}$ and (b) Molecular orbital level of compound $\mathbf{1}$.

In addition, Gaussian 03 not only optimized the computational structure of compound 1 but also obtained its molecular frontier orbitals (Fig. 5b). Its lowest unoccupied molecular (LUMO) level and highest occupied molecular (HOMO) level made it possible for electron transition. For compound 1, the density in the HOMO orbital was primarily concentrated in the salicylaldehyde part; nevertheless, the electron density in the LUMO was distributed throughout the whole molecule. Thus, the change caused by the combination of host and guest in the UV-vis spectra can be explained by the electron transition of the $\mathrm{HOMO}^{37}$.

Application in sample. Fluorescent probes were applied to real samples ${ }^{38}$. Under the optimal conditions, taking the concentration range of $0-1.0 \mathrm{mg} \cdot \mathrm{mL}^{-1}$ of $\mathrm{H}_{2} \mathrm{PO}_{4}^{-}$as an example, the UV-vis absorption of compound 5 was linearly correlated with $\mathrm{H}_{2} \mathrm{PO}_{4}{ }^{-}$'s concentration(see Supplementary Fig. S17), and the correlation coefficient was 0.9945 . The linear regression equation was $\mathrm{A}=0.15414 \mathrm{C}\left(\mathrm{mg} \cdot \mathrm{mL}^{-1}\right)+0.2801(\mathrm{n}=8)$. The $2.0 \mathrm{~g}$ potassium dihydrogen phosphate fertilizer (main content was $1.96 \mathrm{~g}$ ) was dissolved in $50 \mathrm{~mL}$ DMSO and the precipitation was filtered out. The filtrate was then diluted to a main content of $0.392 \mathrm{mg} \cdot \mathrm{mL}^{-1}$. The measured results using the above methods were shown in Table S5. Through the three measurements, the content of $\mathrm{H}_{2} \mathrm{PO}_{4}{ }^{-}$tested in the fertilizer solution reached above $97.5 \%$ of the marked content. It can be seen that there was no significant difference between the content of marker and the result obtained by this method. Recovery experiments were performed on each analyzed samples by adding $0.5 \mathrm{mg} \cdot \mathrm{mL}^{-1}$ of $\mathrm{H}_{2} \mathrm{PO}_{4}{ }^{-}$standard. As shown in the Table $\mathrm{S} 5$, the recovery rates were within the range of $98.5-99.1 \%$, attesting that this method was reliable for the test of $\mathrm{H}_{2} \mathrm{PO}_{4}{ }^{-}$ in fertilizer. The results demonstrated the applicability of the probe to actual samples.

\section{Methods}

The vast majority of raw materials were gained commercially, and all reagents and solvents were analytical reagents. HS ${ }^{-}$was from NaHS, and other anions used were from the tetrabutylammonium salts purchased from Aladdin (Shanghai, People's Republic of China) and did not need to be purified. The solvent dimethyl sulfoxide (DMSO) was gained by reduced pressure distillation after drying by $\mathrm{CaH}_{2} \cdot{ }^{1} \mathrm{H}-\mathrm{NMR}$ information was obtained by a Unity Plus $-400 \mathrm{MHz}$ spectrometer (Bruker, Massachusetts, USA). C, $\mathrm{H}$, and $\mathrm{N}$ elements were analyzed by a Vanio-EL elemental analyzer (Elementar, Philadelphia, PA, USA). Electrospray Ionization with High-Resolution Mass Spectrometry (HRMS (ESI)) was achieved using a Mariner apparatus(Bruker, Massachusetts, USA). At $298 \mathrm{~K}$, an Eclipse fluorescence spectrophotometer (Agilent, State of California, USA) was used for fluorescence experiments; circular dichroism data was measured through a Chirascan (Applied Photophysics, Surrey, UK); an UV2600 UV-vis spectrophotometer (Shimadzu, Kyoto, Japan) was used to perform UV-vis titration. A VersaSTAT 3 Potentiostat Galvanostat (Princeton Applied Research (Ametek), New Jersey, USA) was used for electrochemical experiments. The binding constants $\left(K_{\mathrm{s}}\right)$ were acquired by nonlinear least squares (curve fitting $)^{39-41}$. Five compounds (1-5) were synthesized in light of following procedures.

Synthesis of compound 1: Salicylaldehyde ( $4 \mathrm{mmol}, 0.4966 \mathrm{~g})$ and acetophenone $(2 \mathrm{mmol}, 0.2515 \mathrm{~g})$ were added to the flask and ethanol solution $(15 \mathrm{~mL})$ was poured in to dissolve them. Then, the pale-yellow solution was obtained. Four milliliters of $40 \%(\mathrm{~m} / \mathrm{v}) \mathrm{NaOH}$ solution was added into the mixed solution. The solution developed into yellow with the first drop of $\mathrm{NaOH}$, and then the yellow color deepened stepwise with the continuous dripping of $\mathrm{NaOH}$. After $\mathrm{HCl}(5 \%, 3.5 \mathrm{~mL}, \mathrm{~m} / \mathrm{v})$ was used to adjust the $\mathrm{pH}$ of the solution to 6, a yellow solid formed and was filtered at normal temperature. Next, it was dried in a vacuum environment after washing with high purity water and ethanol. Yield: $74 \%$. m.p. $162-163^{\circ} \mathrm{C} .{ }^{1} \mathrm{H}$ NMR $(400 \mathrm{MHz}$, DMSO) $\delta 10.31$ (s, $1 \mathrm{H}), 8.08$ (dd, $J$ 18.7, $11.5 \mathrm{~Hz}, 3 \mathrm{H}), 7.87(\mathrm{dd}, J 11.1,7.6 \mathrm{~Hz}, 2 \mathrm{H}), 7.66(\mathrm{~d}, J 7.3 \mathrm{~Hz}, 1 \mathrm{H}), 7.57(\mathrm{t}, J 7.5 \mathrm{~Hz}, 2 \mathrm{H}), 7.28(\mathrm{t}, J 7.7 \mathrm{~Hz}, 1 \mathrm{H})$, $6.94(\mathrm{~d}, J 7.5 \mathrm{~Hz}, 1 \mathrm{H}), 6.88(\mathrm{t}, J 7.4 \mathrm{~Hz}, 1 \mathrm{H})$ (see Supplementary Fig. S18). Elemental analysis: Calc. for $\mathrm{C}_{15} \mathrm{H}_{12} \mathrm{O}_{2}$ : C, 80.34; H, 5.39; Found: C, 80.32; H, 5.39. HRMS (ESI) $(\mathrm{m} / z): 247.0731(M+\mathrm{Na})^{+}$(see Supplementary Fig. S19).

Compounds (2-5) were made in an analogous manner.

Compound 2: Yield: 78\%. m.p. $171-173^{\circ} \mathrm{C} .{ }^{1} \mathrm{H}$ NMR (400 MHz, DMSO) $\delta 10.28(\mathrm{~s}, 1 \mathrm{H}), 8.25(\mathrm{~d}, J 2.3 \mathrm{~Hz}, 1 \mathrm{H})$, $8.19(\mathrm{~d}, J 7.2 \mathrm{~Hz}, 2 \mathrm{H}), 8.01(\mathrm{~d}, J 2.6 \mathrm{~Hz}, 2 \mathrm{H}), 7.83(\mathrm{~d}, J 2.3 \mathrm{~Hz}, 1 \mathrm{H}), 7.69(\mathrm{t}, J 7.3 \mathrm{~Hz}, 1 \mathrm{H}), 7.58(\mathrm{t}, J 7.6 \mathrm{~Hz}, 2 \mathrm{H})(\mathrm{see}$ Supplementary Fig. S20). Elemental analysis: Calc. for $\mathrm{C}_{15} \mathrm{H}_{10} \mathrm{Br}_{2} \mathrm{O}_{2}$ : C, 47.16; H, 2.64; Found: C, 80.32; H, 5.39. HRMS (ESI) $(m / z): 382.9111(M+\mathrm{H})^{+}$(see Supplementary Fig. S21).

Compound 3: Yield: 75\%. m.p. $163-165^{\circ} \mathrm{C} .{ }^{1} \mathrm{H}$ NMR (400 MHz, DMSO) $\delta 10.60$ (s, $\left.1 \mathrm{H}\right), 8.19-8.14(\mathrm{~m}, 3 \mathrm{H})$, $7.97(\mathrm{~s}, 2 \mathrm{H}), 7.63(\mathrm{dt}, J 15.1,7.3 \mathrm{~Hz}, 3 \mathrm{H}), 7.42(\mathrm{dd}, J 8.7,2.5 \mathrm{~Hz}, 1 \mathrm{H}), 6.90(\mathrm{~d}, J 8.7 \mathrm{~Hz}, 1 \mathrm{H})$ (see Supplementary Fig. S22). Elemental analysis: Calc. for: $\mathrm{C}_{15} \mathrm{H}_{11} \mathrm{BrO}_{2}$ : C, 60.40; H, 4.43; Found: $\mathrm{C}, 60.39 ; \mathrm{H}, 4.43$. HRMS (ESI) $(m / z): 300.9869(M-H)^{-}$(see Supplementary Fig. S23).

Compound 4. Yield: $68 \%$. m.p. $117-119^{\circ} \mathrm{C} .{ }^{1} \mathrm{H}$ NMR (400 MHz, DMSO) $\delta 11.05(\mathrm{~s}, 1 \mathrm{H}), 8.39(\mathrm{~d}, J 7.7 \mathrm{~Hz}, 1 \mathrm{H})$, $8.15(\mathrm{~d}, J 7.4 \mathrm{~Hz}, 2 \mathrm{H}), 8.12-8.05(\mathrm{~m}, 2 \mathrm{H}), 8.01(\mathrm{~d}, J 15.8 \mathrm{~Hz}, 1 \mathrm{H}), 7.70(\mathrm{t}, J 7.3 \mathrm{~Hz}, 1 \mathrm{H}), 7.59(\mathrm{t}, J 7.6 \mathrm{~Hz}, 2 \mathrm{H}), 7.15$ 
$(\mathrm{t}, J 8.0 \mathrm{~Hz}, 1 \mathrm{H})$ (see Supplementary Fig. S24). Elemental analysis: Calc. for: $\mathrm{C}_{15} \mathrm{H}_{11} \mathrm{NO}_{4}$ : C, 66.91; H, 4.12; N, 5.20; Found: C, 66.92; H, 4.12; N, 5.20. HRMS (ESI) $(\mathrm{m} / z): 268.0615(M-\mathrm{H})^{-}$(see Supplementary Fig. S25).

Compound 5. Yield: $72 \%$. m.p. $210-212^{\circ} \mathrm{C} .{ }^{1} \mathrm{H}$ NMR $(400 \mathrm{MHz}$, DMSO) $\delta 11.93(\mathrm{~s}, 1 \mathrm{H}), 8.84(\mathrm{~s}, 1 \mathrm{H}), 8.19$ (d, $J 8.2 \mathrm{~Hz}, 3 \mathrm{H}), 8.12(\mathrm{~d}, J 15.8 \mathrm{~Hz}, 1 \mathrm{H}), 8.00(\mathrm{~d}, J 15.8 \mathrm{~Hz}, 1 \mathrm{H}), 7.69(\mathrm{t}, J 7.1 \mathrm{~Hz}, 1 \mathrm{H}), 7.59(\mathrm{t}, J 7.6 \mathrm{~Hz}, 2 \mathrm{H}), 7.12(\mathrm{~d}$, $J 9.1 \mathrm{~Hz}, 1 \mathrm{H}$ ) (see Supplementary Fig. S26). Elemental analysis: Calc. for: $\mathrm{C}_{15} \mathrm{H}_{11} \mathrm{NO}_{4}$ : C, 66.91; H, 4.12; N, 5.20; Found: C, 66.92; H, 4.12; N, 5.20. HRMS (ESI) $(\mathrm{m} / \mathrm{z}): 268.0617(M-\mathrm{H})^{-}{ }^{-}$(see Supplementary Fig. S27).

\section{Conclusion}

In summary, we developed five potential chiral molecular probes with "OFF-ON" fluorescence response for $\mathrm{AcO}^{-}, \mathrm{HS}^{-}, \mathrm{F}^{-}, \mathrm{H}_{2} \mathrm{PO}_{4}{ }^{-}$detection. In addition, from $\mathrm{HRMS}$ and chiral means indicated that the binding site of the probe to the anion was on the $\alpha, \beta$-unsaturated ketone structure. By comparison, compound 1 had the best selectivity and compound 5 had the strongest binding ability among the five compounds. And compound 5 had the highest sensitivity to $\mathrm{H}_{2} \mathrm{PO}_{4}^{-}$among the measured anions, and it also can be applied to actual samples.

Received: 15 August 2019; Accepted: 18 November 2019;

Published online: 11 December 2019

\section{References}

1. Zou, J. et al. A novel electrochemical chiral interface based on the synergistic effect of polysaccharides for the recognition of tyrosine enantiomers. Talanta. 195, 628-637 (2019).

2. Đorđević, L. et al. Design principles of chiral carbon nanodots help convey chirality from molecular to nanoscale level. Nat. Commun. 9, 3442 (2018).

3. Shi, X. et al. Enantiorecognition of tyrosine based on a novel magnetic electrochemical chiral sensor. Electrochim. Acta. 241, 386-394 (2017)

4. Calcaterra, A. \& D’Acquarica, I. The market of chiral drugs: chiral switches versus de novo enantiomerically pure compounds. J. Pharmaceut Biomed. 147, 323-340 (2018).

5. Maruoka, K. Design of high-performance chiral phase-transfer catalysts with privileged structures. P. Jpn Acad. B. 95, 1-16 (2019).

6. Fernandes, C. et al. Synthetic chiral derivatives of xanthones: biological activities and enantioselectivity studies. Molecules. 24, 791 (2019).

7. Arabahmadi, R. A selective chemosensor and fluorescence probe for relay recognition of cations and fluoride ions in aqueous media with logic gate function. Talanta. 194, 119-126 (2019)

8. Gale, P. A. \& Caltagirone, C. Fluorescent and colorimetric sensors for anionic species. Coordin. Chem. Rev. 354, 2-27 (2018).

9. Shao, J., Lin, H. \& Lin, H. A novel chromo-and fluorogenic dual responding $\mathrm{H}_{2} \mathrm{PO}_{4}{ }^{-}$receptor based on an azo derivative. Dyes Pigments. 80, 259-263 (2009).

10. Rezaeian, K. \& Khanmohammadi, H. Molecular logic circuits and a security keypad lock based on a novel colorimetric azo receptor with dual detection ability for copper(II) and fluoride ions. Supramol Chem. 28, 256-266 (2016).

11. Zhou, J., Yuan, Y. F., Zhuo, J. B. \& Lin, C. X. Synthesis and characterization of cyclophane: The highly selective recognition of $\mathrm{Fe}^{3+}$ in aqueous solution and $\mathrm{H}_{2} \mathrm{PO}_{4}^{-}$in acetonitrile solution. Tetrahedron Lett. 59, 1059-1064 (2018).

12. Santos-Figueroa, L. E. et al. Chromogenic and fluorogenic chemosensors and reagents for anions. A comprehensive review of the years 2010-2011. Chem Soc Rev. 42, 3489-3613 (2013).

13. Kado, S., Otani, H., Nakahara, Y. \& Kimura, K. Highly selective recognition of acetate and bicarbonate by thiourea-functionalised inverse opal hydrogel in aqueous solution. Chem Commun. 49, 886-888 (2013).

14. Feng, Y. et al. A simple fluorescent film probe for the detection of fluoride anion in organic solution. Dyes Pigments. 153, 200-205 (2018).

15. Spence, G. T., Chan, C., Szemes, F. \& Beer, P. D. Anion binding induced conformational changes exploited for recognition, sensing and pseudorotaxane disassembly. Dalton. T. 41, 13474-13485 (2012).

16. Shang, X. F. et al. Theory and experiment: recognition properties of chemosensor containing ruthenium(II) system in water solution. Sensors Actuat B-Chem. 160, 1112-1119 (2011).

17. Gabr, M. T. \& Pigge, F. C. A fluorescent turn-on probe for cyanide anion detection based on an AIE active cobalt(II) complex. Dalton Trans. 47, 2079-2085 (2018).

18. Li, J. et al. A fluorescein-based "turn-on" fluorescence probe for hypochlorous acid detection and its application in cell imaging. Sensors Actuat B-Chem. 265, 84-90 (2018).

19. Nikfar, Z. \& Shariatinia, Z. Phosphate functionalized $(4,4)$-armchair CNTs as novel drug delivery systems for alendronate and etidronate anti-osteoporosis drugs. J. Mol Graph Model. 76, 86-105 (2017).

20. Slaughter, G., Sunday, J. \& Stevens, B. Energy conversion from aluminium and phosphate rich solution via ZnO activation of aluminium. Mater Chem Phys. 163, 245-252 (2015).

21. Meng, X. et al. Highly sensitive and selective chemosensor for $\mathrm{Cu}^{2+}$ and $\mathrm{H}_{2} \mathrm{PO}_{4}{ }^{-}$based on coumarin fluorophore. Dyes Pigments. 154, 194-198 (2018).

22. Dai, X. et al. An effective colorimetric and ratiometric fluorescent probe for bisulfite in aqueous solution. Anal Chim Acta. 888, 138-145 (2015)

23. Tian, H. et al. A coumarin-based fluorescent probe for differential identification of sulfide and sulfite in CTAB micelle solution. Analyst. 139, 3373-3377 (2014).

24. Lin, Z. H., Zhao, Y. G., Duan, C. Y., Zhang, B. G. \& Bai, Z. P. A highly selective chromo - and fluorogenic dual responding fluoride sensor: naked-eye detection of $\mathrm{F}^{-}$ion in natural water via a test paper. Dalton Trans. 30, 3678-3684 (2006).

25. Dong, H. L., Im, J. H., Lee, J. H. \& Hong, J. I. A new fluorescent fluoride chemosensor based on conformational restriction of a biaryl fluorophore. Tetrahedron Lett. 43, 9637-9640 (2002).

26. He, X. P. et al. Fluorescent glycoprobes: a sweet addition for improved sensing. Chem Commun. 53, 82-90 (2017).

27. Shang, X. et al. Design, synthesis, crystal structure and cytotoxicity studies of colorimetric fluorescent "OFF-ON" probes for rapid detection of hydrogen sulfide based on Cu(II) complex. Inorg Chem Commun. 99, 1-10 (2019).

28. Isaad, J. \& Achari, A. E. Biosourced 3-formyl chromenyl-azo dye as Michael acceptor type of chemodosimeter for cyanide in aqueous environment. Tetrahedron. 67, 5678-5685 (2011).

29. Shang, X. F. et al. Anion recognition and sensing of ruthenium(II) and cobalt(II) sulfonamido complexes. Dalton Trans. 12, 2096-2102 (2009).

30. Velluz, L. Optical Circular Dichroism: Principles, Measurements, And Applications. (Weinheim: Verlag Chemie, New York: Academic Press, 1965).

31. Legrand, M. \& Rougier, M. J. Rotation Spectrum And Circular Dichroism Spectrum. (Henan university press, 1990).

32. Frisch, M. J. Gaussian 03: Revision A.1; Gaussian, Inc. (Pittsburgh PA, 2003). 
33. Carvalho, P. S. Jr. et al. X-ray diffraction and theoretical investigation of the gedunin crystal structure. J. Mol Struct. 1008, 83-87 (2012).

34. Brasil, D. S. B. et al. Isolation, X-ray crystal structure and theoretical calculations of the new compound 8-Eepicordatin and identification of others terpenes and steroids from the bark and leaves of Croton palanostigma Klotzsch. J. Braz. Chem. Soc. 21, 731-739 (2010).

35. Maity, D., Bhaumik, C., Mondal, D. \& Baitalik, S. Photoinduced intramolecular energy transfer and anion sensing studies of isomeric Ru II Os II complexes derived from an asymmetric phenanthroline-terpyridine bridge. Dalton Trans. 43, 1829-1845 (2014).

36. Ni, X. L. et al. Ditopic receptors based on lower-and upper-rim substituted hexahomotrioxacalix arenes: cation-controlled hydrogen bonding of anion. Chem Asian J. 7, 519-527 (2012).

37. Shang, X. F. et al. Synthesis and binding ability of molecular probes based on a phenanthroline derivative: theory and experiment. Molecules. 18, 14840-14848 (2013).

38. Wang, L. P., Yang, X. F., Xu, H. M. \& Zhao, M. L. A highly sensitive fluorescent probe for tiopronin based on the cleavage of 2, 4-dinitrobenzenesulfonate. Luminescence. 24, 295-299 (2009).

39. Bourson, J., Pouget, J. \& Valeur, B. Ion-responsive fuorescent compounds. 4. Efect of cation binding on the photophysical properties of a coumarin linked to monoaza- and diaza-crown ethers. J. Phys. Chem. 97, 4552-4557 (1993).

40. Liu, Y., You, C. C. \& Zhang, H. Y. Supramolecular Chemistry. (Nankai University Publication, Tianjin, 2001).

41. Liu, Y., Han, B. H., Zhang, H. Y. Spectroscopic studies on molecular recognition of modified cyclodextrins. Curr. Org. Chem. 8, $35-46(2004)$

\section{Acknowledgements}

This work was supported by the Fund of Science \& Technology Innovation Talents in Universities of Henan Province (15HASTIT039), Fluorescence Probe and Biomedical Detection Research Team of Xinxiang City (CXTD16001), Scientific and Technological Research Projects of Henan Province (182102311124), the Natural Science Foundation of Henan Province (182300410118), the Graduate Scientific Research Innovation Support Project of Xinxiang Medical University (YJSCX201840Y).

\section{Author contributions}

X.S., Y.W., T.W., X.X. directed the work. C.L. and L.L. conceived the idea and designed the experiments. C.L., W.P. and Y.C. performed the synthesis and spectral determination. X.X. completed the theoretical investigation. C.L. wrote the manuscript. All authors reviewed the manuscript.

\section{Competing interests}

The authors declare no competing interests.

\section{Additional information}

Supplementary information is available for this paper at https://doi.org/10.1038/s41598-019-55421-2.

Correspondence and requests for materials should be addressed to X.S.

Reprints and permissions information is available at www.nature.com/reprints.

Publisher's note Springer Nature remains neutral with regard to jurisdictional claims in published maps and institutional affiliations.

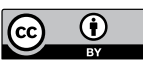

Open Access This article is licensed under a Creative Commons Attribution 4.0 International License, which permits use, sharing, adaptation, distribution and reproduction in any medium or format, as long as you give appropriate credit to the original author(s) and the source, provide a link to the Creative Commons license, and indicate if changes were made. The images or other third party material in this article are included in the article's Creative Commons license, unless indicated otherwise in a credit line to the material. If material is not included in the article's Creative Commons license and your intended use is not permitted by statutory regulation or exceeds the permitted use, you will need to obtain permission directly from the copyright holder. To view a copy of this license, visit http://creativecommons.org/licenses/by/4.0/.

(c) The Author(s) 2019 